\title{
A BIODEGRADABLE GENTAMICIN-HYDROXYAPATITE-COATING FOR INFECTION PROPHYLAXIS IN CEMENTLESS HIP PROSTHESES
}

\author{
D. Neut ${ }^{1,2, *}$, R.J.B. Dijkstra ${ }^{1}$, J.I. Thompson ${ }^{3}$, C. Kavanagh ${ }^{4}$, H.C. van der Mei $^{1}$ and H.J. Busscher ${ }^{1}$
}

\begin{abstract}
${ }^{1}$ University of Groningen and University Medical Center Groningen, Department of Biomedical Engineering and ${ }^{2}$ Department of Orthopaedic Surgery, Antonius Deusinglaan 1, 9713 AV Groningen, The Netherlands. ${ }^{3}$ DePuy Synthes Joint Reconstruction, Number One, White Rose Office Park, Millshaw Park Lane,

Leeds LS11 0BG, UK.

${ }^{4}$ DePuy Ireland, Loughbeg, Ringaskiddy, Cork, Ireland.
\end{abstract}

\begin{abstract}
A degradable, poly (lactic-co-glycolic acid) (PLGA), gentamicin-loaded prophylactic coating for hydroxyapatite (HA)-coated cementless hip prostheses is developed with similar antibacterial efficacy as offered by gentamicinloaded cements for fixing traditional, cemented prostheses in bone. We describe the development pathway, from in vitro investigation of antibiotic release and antibacterial properties of this PLGA-gentamicin-HA-coating in different in vitro models to an evaluation of its efficacy in preventing implant-related infection in rabbits. Bone in-growth in the absence and presence of the coating was investigated in a canine model. The PLGAgentamicin-HA-coating showed high-burst release, with antibacterial efficacy in agar-assays completely disappearing after 4 days, minimising risk of inducing antibiotic resistance. Gentamicin-sensitive and gentamicinresistant staphylococci were killed by the antibiotic-loaded coating, in a simulated prosthesis-related interfacial gap. PLGA-gentamicin-HA-coatings prevented growth of bioluminescent staphylococci around a miniature-stem mounted in bacterially contaminated agar, as observed using bio-optical imaging. PLGA-gentamicin-HA-coated pins inserted in bacterially contaminated medullary canals in rabbits caused a statistically significant reduction in infection rates compared to HA-coated pins without gentamicin. Bone ingrowth to PLGA-gentamicin-HAcoated pins, in condylar defects of Beagle dogs was not impaired by the presence of the degradable, gentamicinloaded coating. In conclusion, the PLGA-gentamicinHA-coating constitutes an effective strategy for infection prophylaxis in cementless prostheses.
\end{abstract}

Keywords: cementless prosthesis, gentamicin-releasing coating, hydroxyapatite, antibiotic release, antibacterial efficacy, bone ingrowth.

*Address for correspondence:

Dr. D. Neut

Department of Biomedical Engineering (FB40)

W.J. Kolff Institute

University of Groningen and University Medical Center Groningen

PO Box 196, 9700 AD Groningen, The Netherlands

Tel: $+31-50-3633140$

Fax: +31-50-3633159

E-mail: d.neut@umcg.nl

\section{Introduction}

Total hip replacements have been performed since the early 1960s on patients suffering from hip joint arthrosis. At present, total hip replacement has an incidence higher than 150 procedures per 100,000 habitants in most industrialised countries, and accordingly about one million hips are replaced by prostheses worldwide every year (Web ref. 1). On average, the incidence rate of this procedure has increased by $25 \%$ between 2000 and 2009 and this trend is predicted to continue due to ageing populations and growing prevalence of obesity (Web ref. 1). Projection models claim that the incidence of total hip replacement is expected to increase at least until 2030 in the United States (Kurtz et al., 2014; Nemes et al., 2014), which is likely a worldwide valid prediction. From the onset, high infection rates have plagued patients and treating orthopaedic surgeons. Nevertheless, total hip replacement is, at the same time, amongst the clinically most successful procedures, providing almost immediate relief of pain and restoration of function. Along with the projected increase in incidence of total hip replacement, is an increase in the numbers of patients suffering from infection. Although infections rates may be considered low at around 1-2\% (Hamilton and Jamieson, 2008), the economical downside of infection makes 1-2\% unacceptably high, due to the enormous number of implant recipients (Kurtz et al., 2014). Moreover, many patients have a severely reduced quality of life after an episode of infection (Helwig et al., 2014).

Despite the use of local and systemic antibiotic prophylaxis, strict hygiene protocols, and special sterile enclosures with laminar flow during surgery, the deep infection rate of primary hip replacements remains between $1 \%$ and $2 \%$ (Hamilton and Jamieson, 2008). Based on past experiences (Knobben et al., 2006), it seems likely that improving hygiene and surgical discipline are insufficient countermeasures to prevent peri-operative contamination of implant surfaces. This is especially true for hip and knee replacements, often still requiring long incisions and surgical times of 1-2 $\mathrm{h}$. When peri-operatively introduced bacteria are able to grow into a biofilm that protects the colonising organisms against the host immune system and antibiotics, the fate of the implant is a race for the surface between host tissue integration and bacterial colonisation (Gristina, 1987). This frequently results in surgical removal and subsequent replacement of the implant, at considerable costs (Vanhegan et al., 2012). In vitro (Subbiahdoss et al., 2010) as well as clinical evaluations (Deacon et al., 1996) have demonstrated that tissue integration provides protection against infection. 
This is especially important for the long-term protection of an implant against post-operative spreading of bacteria disseminated from infections elsewhere in the body or entering the bloodstream after routine dental treatments (Walman et al., 1997).

Polymethylmethacrylate bone cement has traditionally been used to bond prosthetic replacements into bone. The use of antibiotic-loaded bone cements has been demonstrated to yield a lower risk of both septic (Engesaeter et al., 2003; Wang et al., 2013) and aseptic, or possibly more accurately "presumed aseptic" loosening than unloaded cements (Parvizi et al., 2011) in primary prostheses as well as in revision surgery, despite administration of systemic antibiotic prophylaxis. In addition, local antibiotic delivery from bone cements has been proven to yield prophylactic effects against postoperative infections both in experimental and clinical studies (Malchau et al., 2002; Tunney et al., 2007). The Norwegian Arthroplasty Register (containing a total of 97,344 total hip replacements) indicated that there was a broad and consistent use of cemented prostheses over the period 1987-2007, representing about $85 \%$ of all replacements (Dale et al., 2009). Register data also indicate a continuous increase in the use of antibiotic-loaded cements, from $45 \%$ in the period 1987-1992 up to $99 \%$ in the period 2003-2007 (Dale et al., 2009). Consequently, orthopaedic surgeons all over Europe now routinely use antibiotic-loaded bone cements in all cemented primary hip replacements and revision surgeries, and cemented fixation remains a common clinical solution.

Lately, due to progressive improvements in prosthesis design and changes in prosthetic material, providing better osseointegration, cementless prostheses have experienced increasing popularity and growth in use especially in younger and more active patients. Important in the increasing popularity of cementless prostheses is the development of grit-blasted, porous or hydroxyapatite (HA) coatings to stimulate osseointegration. Grit-blasting is known to stimulate osseointegration, and coating of prostheses with calcium phosphate ceramics, such as HA (Oosterbos et al., 2004), further enhance bone bonding in a relatively short period of time (Geesink et al., 1987; Søballe et al., 1993) under load-bearing conditions (Søballe et al., 1990). Clinically, osseointegration allowing full weightbearing occurs within 4 to 12 weeks (Markmiller et al., 2011). As a result of these developments, currently in the United States, about $90 \%$ of all femoral stems implanted use cementless procedures (Web ref. 2). However, as a result of the use of cementless prostheses, antibiotic-loaded bone cements will no longer be available for prophylaxis to reduce risks of peri-operative bacterial contamination. Presently, no effective strategies are clinically available for local antibiotic prophylaxis in the case of cementless prostheses. A recent report shows that while infection rates associated with total hip replacements are increasing in general, the increase is most marked in the case of cementless hip replacements (Dale et al., 2009).

In vitro experiments indicated that gentamicinreleasing coatings on grit-blasted titanium surfaces for use as cementless prostheses, with $1.0 \mathrm{mg}$ gentamicin/ $\mathrm{cm}^{2}$ of the antibiotic sandwiched between the surface and a biodegradable overlayer, possess a similar antibacterial efficacy as clinically employed gentamicin-loaded bone cements (Neut et al., 2011). However, no such antibioticreleasing coating has been described for cementless HAcoated prostheses.

This study describes the development of a new, robust HA-coating containing gentamicin on titanium alloy (Ti6Al-4V) covered with a protective, biodegradable poly (lactic-co-glycolic acid) (PLGA)-overlayer, that prevents colonisation of cementless orthopaedic prostheses by perioperatively introduced bacteria. Initial in vitro experiments describe evaluation of the gentamicin release characteristics and antibacterial efficacies of the PLGA-gentamicin-HAcoatings against a number of staphylococcal strains, among which two were gentamicin-resistant. Staphylococcal strains were used since staphylococci constitute the number one causative strain for orthopaedic implant infection (Zimmerli et al., 2004). Antibacterial efficacy was determined using traditional zone of inhibition measurements on agar plates, but also using models to analyse antibacterial efficacies in confined spaces and in a geometrically relevant set-up with miniature stems, using bio-optical imaging. In vivo evaluation of the antibacterial efficacy of the PLGA-gentamicin-HA-coating was carried out in a contaminated prosthesis model in rabbits, while effects of the coating on bone fixation and osseointegration were assessed in a canine condylar defect model, to demonstrate technology potential for clinical translation.

\section{Materials and methods}

\section{PLGA-gentamicin-HA-coated titanium coupons, miniature stems, and pins}

The Ti-6Al-4V surface was grit-blasted with alumina grit. Grit-blasting is used to roughen the surface to obtain better mechanical adhesion of the HA-coating. After cleaning ultrasonically in purified water and passivating, HA was spray-coated on the grit-blasted Ti-6Al-4V, according to DePuy's standard specification for the clinically established Corail ${ }^{\circledR}$ total hip system (plasma sprayed HA with a thickness of $155 \mu \mathrm{m}$, as per the detailed specification described by Reignier et al. (2011)). Gentamicin sulphate (Lek Pharmaceuticals, Slovenia) was applied on HA-coated, grit-blasted Ti-6Al-4V coupons (diameter $2.5 \mathrm{~cm}$; height $0.4 \mathrm{~cm}$; surface area $4.9 \mathrm{~cm}^{2}$ ) using a proprietary spraying technique (Web ref. 3 ) and its surface concentration was adjusted to $1 \mathrm{mg} / \mathrm{cm}^{2}$ bioactive gentamicin. This concentration was chosen, because on grit-blasted Ti-6Al-4V surfaces, this gentamicin surface concentration yielded a similar antibacterial efficacy to that of gentamicin-loaded bone cement (Neut et al., 2011). The gentamicin surface concentration of $1 \mathrm{mg} / \mathrm{cm}^{2}$ is controlled through the process by spray time and the gentamicin content is checked by an HPLC method. Finally, a PLGA layer (PURAC ${ }^{\circledR}$ 5002, Purac Biochem, Gorinchem, The Netherlands) with a methyl ester as the terminal functional group was applied over the HA-containing gentamicin coating using an ultrasonic coating process. The PLGA used had an inherent viscosity of 0.2 (molecular weight of $17 \mathrm{kDa}$ ) and a 50:50 molar ratio of PLA: PGA. This 


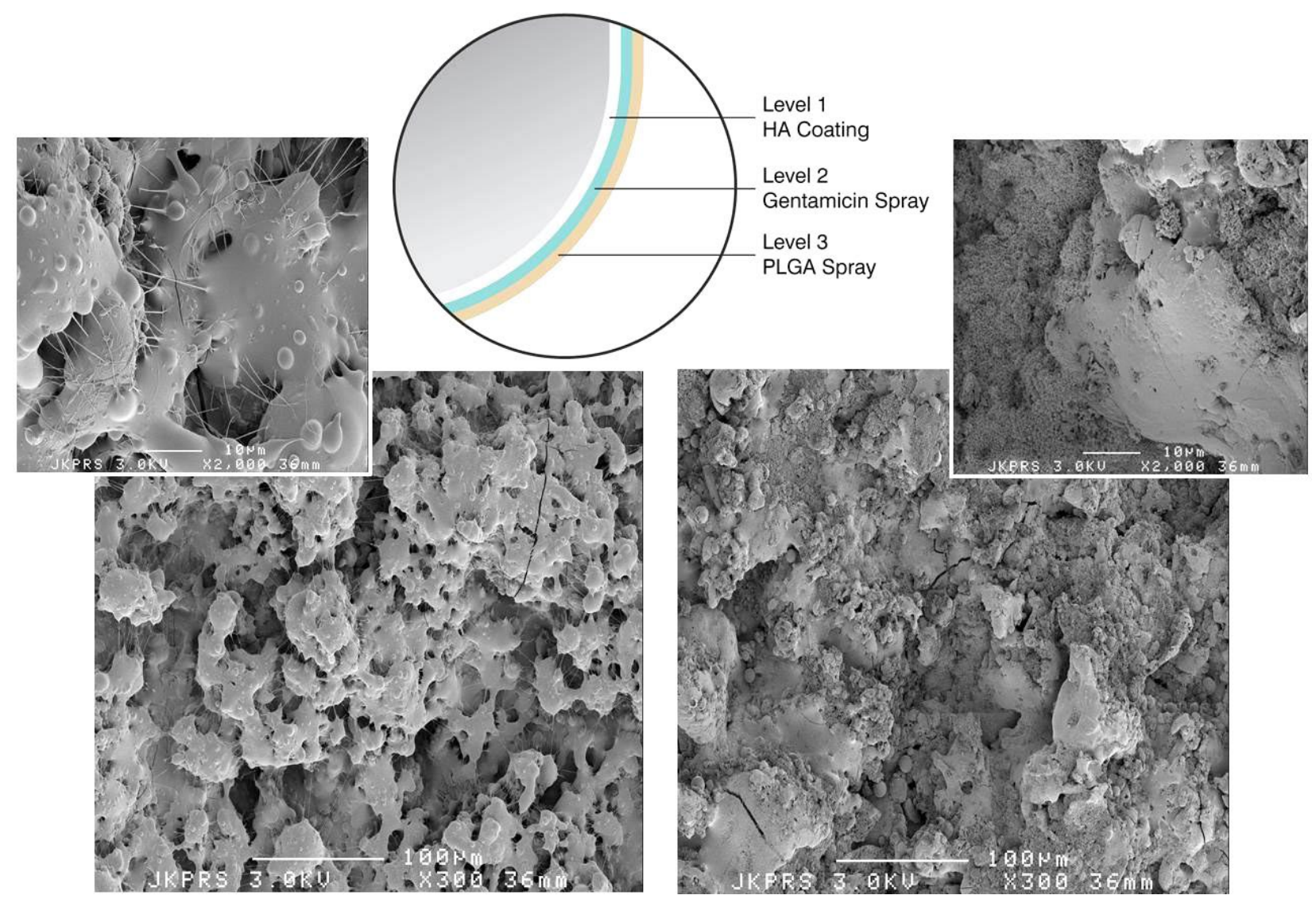

Fig. 1. Scanning electron micrographs of a PLGA-gentamicin-HA-coating prior to (left) and after gentamicin-release during 2 weeks in PBS (right), together with a schematic presentation of the built-up of the coating, including the protective PLGA-overlayer. The bar equals $100 \mu \mathrm{m}$ for low magnification micrograph, and $10 \mu \mathrm{m}$ for the insert.

thin PLGA-overlayer serves as a biodegradable layer to protect the gentamicin layer during transit and surgical implantation and not a priori to control antibiotic release. It quickly degrades in vivo to ensure normal osseointegration.

In addition, PLGA-gentamicin-HA-coated, grit-blasted Ti-6Al-4V miniature stems (diameter $1.2 \mathrm{~cm}$ and length $10.0 \mathrm{~cm}$ ) and pins (diameter of $0.25 \mathrm{~cm}$, length of $4.5 \mathrm{~cm}$ for the infection prophylaxis model, and diameter of $0.5 \mathrm{~cm}$, length of $1.5 \mathrm{~cm}$ for the bone ingrowth studies) with a protective PLGA-overlayer were made. Fig. 1 presents a schematic overview of the different coating layers.

All coupons (HA- and PLGA-gentamicin-HA-coated), miniature stems, and pins were manufactured (DePuy Ireland, Cork, Ireland) under conditions employed for manufacturing implants and were supplied in individual 25 kGy gamma-sterilised surgical packs.

\section{Gentamicin release}

In order to establish the longevity of the gentamicin release from the PLGA-gentamicin-HA-coating, coupons were immersed in $20 \mathrm{~mL}$ of sterile phosphate buffered saline (PBS; $\mathrm{NaCl} 8.76 \mathrm{~g} / \mathrm{L}, \mathrm{K}_{2} \mathrm{HPO}_{4} 43.5 \mathrm{~g} / \mathrm{L}, \mathrm{KH}_{2} \mathrm{PO}_{4}$ $34.5 \mathrm{~g} / \mathrm{L}, \mathrm{pH} 7.4$ ) and incubated at $37^{\circ} \mathrm{C}$, as described before in a study on gentamicin-coatings in absence of HA (Neut et al., 2011). At designated time intervals (1, $6,24,30,48,72,168$ and $336 \mathrm{~h}), 500 \mu \mathrm{L}$ aliquots of the gentamicin-PBS solution were removed and stored at $4{ }^{\circ} \mathrm{C}$ for subsequent determination of the gentamicin concentration. Gentamicin concentrations were determined by a fluorescence polarisation immuno-assay, having a sensitivity of $0.30 \mu \mathrm{g} / \mathrm{mL}$ and an assay sample range of 0.44-13.80 $\mu \mathrm{g} / \mathrm{mL}$ (AxSYM, Abbott Laboratories, USA). Samples with gentamicin concentrations reported as greater than $10.00 \mu \mathrm{g} / \mathrm{mL}$ were diluted.

\section{Scanning electron microscopy (SEM)}

The surfaces of the PLGA-gentamicin-HA-coated coupons before and after complete gentamicin release were investigated using SEM, as described before in a study on gentamicin-coatings in absence of HA (Neut et al., 2011). Examination was done at $2.0 \mathrm{kV}$ in a JEOL field emission scanning electron microscope type 6301F. Coupons were sputter-coated with a $3 \mathrm{~nm}$ thick conductive layer of gold/ palladium $(80 / 20)$.

\section{Bacterial strains for in vitro studies}

Six staphylococcal strains were used in the in vitro parts of this study, including two gentamicin-resistant strains, with minimal inhibitory concentration (MIC) $>4 \mu \mathrm{g} / \mathrm{mL}$. S. aureus 5298 (MIC gentamicin $=0.2 \mu \mathrm{g} / \mathrm{mL}$ ), S. aureus 7323 (MIC gentamicin $=1.5 \mu \mathrm{g} / \mathrm{mL}$ ), S. epidermidis 7388 (MIC gentamicin $>256 \mu \mathrm{g} / \mathrm{mL}$ ), and S. epidermidis 7391 (MIC gentamicin $=24 \mu \mathrm{g} / \mathrm{mL}$ ) were obtained from patients with infected joint arthroplasties and retrieved 
during revision surgery (Department of Orthopaedic Surgery at the University Medical Center Groningen, The Netherlands). In addition, we used one ATCC strain S. aureus ATCC 12600 (MIC gentamicin $=1 \mu \mathrm{g} / \mathrm{mL}$ ) and one bioluminescent strain S. aureus Xen36 (MIC gentamicin $=0.75 \mu \mathrm{g} / \mathrm{mL}$ ). The bioluminescent strain produces luciferase and its substrate constitutively, resulting in a photon-emitting state when metabolically active. This strain was obtained commercially from Perkin Elmer (Massachusetts, USA). The MIC of gentamicin for all strains was determined using the E-test (Biomerieux, MarcyI'Etoile, France).

Staphylococci were cultured from cryopreservative beads (Protect Technical Service Consultants Ltd., United Kingdom) onto blood agar plates at $37{ }^{\circ} \mathrm{C}$ in ambient air for $24 \mathrm{~h}$. For the preparation of experimental cultures, one colony was inoculated into a $10 \mathrm{~mL}$ batch culture of Tryptone Soya Broth (TSB: Oxoid, UK), cultured for $18 \mathrm{~h}$ at $37^{\circ} \mathrm{C}$, and this overnight culture was diluted with TSB to an optical density (at $600 \mathrm{~nm}$ ) of 0.1 which equals approximately $10^{8}$ bacteria $/ \mathrm{mL}$.

\section{Antibacterial efficacy of the PLGA-gentamicin-HA- coating}

Longevity of the antibacterial efficacy

To determine the $24 \mathrm{~h}$ bacterial growth inhibition of the coating and its longevity, staphylococcal cultures were used to inoculate TSA plates with a sterile cotton swab, according to methodological details described before (Neut et al., 2011). Ten minutes after inoculation, the PLGAgentamicin-HA-coated coupons were placed in the centre of each plate, with little or no additional pressure. Agar plates were incubated for $24 \mathrm{~h}$ at $37^{\circ} \mathrm{C}$ in ambient air, after which the width of the inhibition zones for each sample were measured. The inhibition zone was calculated by subtracting the diameter of the coupon from the inhibition zone diameter and dividing the difference by two. The experiments were done in triplicate with separately grown bacterial cultures and on separate agar plates. Immediately following the first zone of inhibition measurement, coupons were transferred to a freshly inoculated agar plate every $24 \mathrm{~h}$ to determine the longevity of the gentamicin release. This was repeated on a daily basis up to 4 days.

\section{Bacterial killing in an interfacial gap}

To determine the bacterial killing of PLGA-gentamicinHA-coating in a confined spacing, the $3 \mathrm{M}$ Petrifilm Aerobic Count (AC) medium system was used, as described before from a methodological perspective (Neut et al., 2011). A Petrifilm AC plate (3M Microbiology, St. Paul, USA) consists of two films, a bottom film containing standard nutrients, a cold-water gelling agent, and an indicator dye that facilitates colony counting, and a top film enclosing the sample within the Petrifilm system. The bottom film containing the gelling-agent can be inoculated with sterile demineralised water after which both films are pressed together and gelling occurs after $30 \mathrm{~min}$. For the current experiments, $50 \mu \mathrm{L}$ aliquots of bacteria suspended in fresh TSB to different concentrations between $10^{3}$ and $10^{9}$ bacteria $/ \mathrm{mL}$, as determined in a Bürker-Türk counting chamber, was placed on top of a PLGA-gentamicin-
HA-coated coupon after which the Petrifilm was folded together. Petrifilm plates were incubated at $37^{\circ} \mathrm{C}$ for $48 \mathrm{~h}$ and colony forming units (CFU) counts determined. On average, the bacterial suspension spread to a diameter of $2.5 \mathrm{~cm}$, implying a confined spacing with a thickness of $100 \mu \mathrm{m}$. Multiplication of the suspension volume $(50 \mu \mathrm{L})$ with the bacterial concentration yields the total bacterial challenge per coupon $\left(4.9 \mathrm{~cm}^{2}\right)$. All experiments were done in triplicate with separately prepared bacterial suspensions.

\section{Bioluminescence imaging}

Potential suitability of the PLGA-gentamicin-HA-coating for use in total hip replacement is further assessed by determining its ability to prevent bacterial growth in a biofilm assay. Longitudinal bacterial growth prevention of a gentamicin-coating in absence of HA was demonstrated using a recent geometrically-relevant model in which a gentamicin-coated miniature stem was mounted in an aqueous agar surrounding into which the gentamicin released could diffuse, as described in detail before (Neut et al., 2012). In short, the stem-holder allowed placement of a stem in its centre through a slot over half the depth of the bottom plate. The sterilised stem-holder was filled with liquid TSA with a sterile uncoated miniature stem in place. After cooling and solidification of the agar, the stem was removed, creating a perfect mould of the stem in the centre of the agar.

A culture of bioluminescent $S$. aureus Xen36 in TSB was then diluted and suspended to a concentration of $1 \times 10^{4}$ bacteria/ml in fresh TSB. These suspensions were used to contaminate the inside of the mould using a cotton swab. To this end, a sterile cotton swap was dipped 3 times in the bacterial suspension and gently moved over the inner mould surface. This procedure yielded transfer of approximately 150 bacteria from the swab to the mould surface (Neut et al., 2012), corresponding with 4 bacteria $/ \mathrm{cm}^{2}$ mould surface. This represents a clinically realistic bacterial challenge based on available data on peri-operative contamination during a $1 \mathrm{~h}$ surgery in operating theatres with conventional ventilation systems (Sossai et al., 2011; Verkkala et al., 1998; Fitzgerald, 1979). After $10 \mathrm{~min}$ of drying, a sterile HA-coated or PLGA-gentamicin-HA-coated miniature stem was inserted and the entire system was incubated for $60 \mathrm{~h}$ at $37^{\circ} \mathrm{C}$ in a bio-optical imaging system.

Bioluminescence was imaged with a CCD camera (IVIS ${ }^{\circledR}$ Lumina II, Caliper Life Sciences, Hopkinton, MA, USA) directly following insertion of the stem on an hourly basis throughout the experimental period up to $60 \mathrm{~h}$. A bioluminescent image was obtained with 5 min exposure time using $7.5 \mathrm{~cm}$ field of view and $5 \mathrm{~cm}$ sample height, binning of $4,1 / f$ stop and open filter. Bioluminescence imaging was performed with the top cover of the stem holder removed, thus focusing on the top of the agar and imaging bioluminescence along the length of the stem. As a region of interest (ROI), a circular shell was taken around the stem. To this end, two circular ROIs were first defined: one with a diameter coinciding with the diameter of the miniature stem and one with a larger diameter of $3.0 \mathrm{~cm}$ around the centre (insert Fig. 4). Subsequently, the bioluminescences from both ROIs were subtracted 
to yield the bioluminescence arising from the colonised zone around the stem. Bioluminescence was quantified as total bioluminescent flux ( $\mathrm{p} / \mathrm{s}$ ) within the circular shell by using Living Image ${ }^{\circledR} 3.0$ software (Xenogen, Alameda, CA, USA). The experiments were done in triplicate with separately cultured bacteria.

\section{Animal experiments - infection prophylaxis model Study design}

The study was carried out in four groups with a total of 14 female New Zealand White albino rabbits. Two groups (HA- and PLGA-gentamicin-HA-coated pins) were sacrificed at day 2 post-operatively ( 3 animals/ group) and two similar groups were sacrificed at day 7 post-operatively (4 animals/group). The group sizes were determined by the following power calculation: at day 2 , we anticipated a mean CFU count of $6 \log (S D=3)$ in the HA-coated group and in the PLGA-gentamicin-HA-coated group $\leq 1 \log (S D=1)$. With an alpha level of 0.05 and a power of $80 \%$, sample size needed in each group was 3 animals. At day 7, we anticipated a mean CFU count of $7 \log (S D=4)$ in the HA-coated group and again $\leq 1 \log$ $(S D=1)$ in the PLGA-gentamicin-HA-coated group. With an alpha level of 0.05 and a power of $80 \%$, sample size needed in each group was 4 animals.

All experiments were carried out at a contract research facility (MPI Research, Mattawan, MI, USA). The study design was approved by MPI Research in compliance with all applicable regulations governing care and use of laboratory animals in the USA.

\section{Surgical procedure}

Surgery was carried out under aseptic conditions, after performing anaesthesia and starting pain management. Skin incision was made over the greater trochanter of the right limb and the gluteal muscles were retracted to allow access to the piriformis fossa. A hole with the final size of $2.5 \mathrm{~mm}$ was created by inserting a $1.0 \mathrm{~mm}$ Kirschner wire (K-wire) into the femur/medullary canal and subsequently the hole was gradually enlarged, to prevent fracture of the cortical bone, by drilling over the K-wire with a $2.0 \mathrm{~mm}$ and a $2.5 \mathrm{~mm}$ drill bit. After the hole was created, the medullary canal was flushed with sterile saline to remove most of the marrow.

The medullary canal was inoculated with gentamicinsensitive $S$. aureus ATCC 25923 (MIC gentamicin $=1 \mu \mathrm{g}$ / $\mathrm{mL}$ ) (Hess et al., 2011) using a micropipette. Each animal received $100 \mu \mathrm{L}$ of a bacterial suspension $\left(1 \times 10^{6} \mathrm{CFU} /\right.$ $\mathrm{mL}$ ) to a final dose of $1 \times 10^{5} \mathrm{CFU}$ per site. This inoculation dose was chosen due to results of a pilot study, showing induction of infection without causing death of the animals. An HA- or PLGA-gentamicin-HA-coated pin was inserted into the canal using an insertion tool to avoid direct handling of the implant surface. Once the pin was placed, the defect opening was filled with bone wax, muscle and subcutaneous layers were sutured in a routine fashion, and the skin was closed with skin glue.

The animals were euthanised at day 2 or 7 and the right femur was harvested under sterile conditions. Macroscopic observations of the implant sites (e.g. abscess formation or cortical lysis) were recorded. The distal third of the femur was removed using surgical rongeurs and the pin was explanted from the medullary canal. The distal and proximal femur segments and the pin itself were collected in separate sterile containers.

\section{Microbiological evaluation}

Samples of bone adjacent to the pins were weighed on receipt and placed in $50 \mathrm{~mL}$ tubes. If the samples weighted over $2 \mathrm{~g}$, they were cut up using sterile instruments. Five $\mathrm{mL}$ of sterile saline per $\mathrm{g}$ bone was added to each tube and bone samples were homogenised for 1 min using a Polytron homogeniser PT 1200 E (Kinematica AG). The pins were transferred to a sterile $15 \mathrm{~mL}$ tube and $5.5 \mathrm{~mL}$ of TSB medium was added to each tube. Pins were sonicated for $7 \mathrm{~min}$ at $40 \mathrm{kHz}$ and $150 \mathrm{~W}$ using a Crest Ultrasonics Sonicator and then vortexed for $3 \mathrm{~min}$. All samples were kept on ice water in order to avoid bacterial growth.

Standard 96-well microdilution plates (Costar 3795; Fisher Scientific, Pittsburgh, US) were filled with $270 \mu \mathrm{L}$ sterile saline or TSB medium, except for column 1. Three hundred $\mu \mathrm{L}$ of sample was loaded into column 1 and the samples were serially diluted 10 -fold across the plate. From columns 1-8 (undiluted sample through the $10^{-7}$ dilution), $10 \mu \mathrm{L}$ aliquots were spotted in duplicate across the top of a square agar plate. The agar plates were then tilted at a $45-90^{\circ}$ angle to allow the $10 \mu \mathrm{L}$ aliquot to track across the agar surface to the opposite side of the plate. The plates were laid flat, allowed to dry at room temperature, inverted, and incubated at $35^{\circ} \mathrm{C}$ for $24-48 \mathrm{~h}$. Colonies were manually counted and counts were converted to log-units CFU per gram bone or per pin.

\section{Haematological evaluation}

Haematological evaluations were conducted pre-operatively for all animals, on days 1 and 2 post-operatively for animals in the day- 2 sacrifice groups, and on days 4 and 7 postoperatively for the animals in the day-7 sacrifice groups. Blood samples were taken from the jugular vein. Samples were placed in tubes containing ethylenediaminetetraacetic acid for evaluation of haematology parameters (leukocyte count -total and absolute differential-, erythrocyte count, haemoglobin, haematocrit, absolute reticulocytes, platelet count, and blood cell morphology) using an automated haematological analyser ABX Micros ES 60 (HORIBA Medical, Kyoto, Japan).

\section{Animal experiments - bone ingrowth model \\ Study design}

The study was carried out in four groups with a total of 12 male Beagles at a contract research facility (MPI Research, Mattawan, MI, USA). The study design was approved by MPI Research in compliance with all applicable regulations governing care and use of laboratory animals in the USA. Beagles were selected because of their wide-spread use for evaluating implants in bone (Turner, 2001). Additionally, the Beagle distal femoral condyle is sufficiently large to hold two implants per knee, reducing the number of animals required for the study. Two groups (HA- and PLGA-gentamicin-HA-coated pins) were sacrificed at week 4 post-operatively ( 5 animals), and two similar groups were sacrificed at week 12 post-operatively ( 7 animals). 
The group sizes were determined by the following power calculation: at week 4, we anticipated a mean bone-implant contact of $40 \%(S D=6 \%)$ in the HA-coated group and $30 \%(S D=5 \%)$ in the PLGA-gentamicin-HA-coated group. With an alpha level of 0.05 and a power of $80 \%$, sample size needed in each group was 5 animals. At week 12, we anticipated a mean bone-implant contact of $60 \%$ $(S D=7 \%)$ in the HA-coated group and $50 \%(S D=6 \%)$ in the PLGA-gentamicin-HA-coated group. With an alpha level of 0.05 and a power of $80 \%$, sample size needed in each group was 7 animals.

The 4-week period is regarded as the time required for initial bone ingrowth and fixation of the pin, while the time point of 12 weeks was added as further data on mediumterm bone integration (Alt et al., 2011; Bobyn et al., 2009; Moojen et al., 2009).

\section{Surgical procedure}

After induction of anaesthesia, each animal was placed on its side on the surgical table and a skin incision was made over the distal femur. The skin was retracted and the muscle and soft tissue over the femur were reflected to expose the lateral condyle. Two circular defects, approximately 4.8 to $5.4 \mathrm{~mm}$ in diameter, were placed 12 to $17 \mathrm{~mm}$ apart (from centre of defect to centre of defect) parallel to the distal femur condylar plateau. Each defect was drilled perpendicular to the lateral condyle surface, through the cortex, until the medullary cavity was breached. The first defect was created in the approximate centre of the lateral condyle and the second defect positioned relative to the first.

All pins were handled using a specifically designed insertion tool and they were placed so that the pin was surrounded by cancellous bone and not in contact with the opposing cortical bone. Once each pin had been placed, the drilled bone defect was filled with bone wax, the muscle and subcutaneous layers were sutured in a routine fashion, and the skin was closed with skin glue. The animal was repositioned on its opposite side and the procedure was repeated on the contralateral femur.

At the end of the 4 and 12 week recovery periods, the animals were euthanised by an intravenous overdose of sodium pentobarbital solution followed by exsanguination by severing of the femoral or axillary vessels. The left and right distal femora were removed.

\section{Biomechanical testing}

Each condyle was potted in dental cement making sure the cement did not come into contact with the pin directly or through the cancellous bone bed. The potted specimen was mounted directly under the pull-out grip and positioned so that the axis of the pin was aligned in parallel with the direction of the pull-out force. The pull-out grip was centred over the specimen and raised at a rate of $1 \mathrm{~mm} /$ min. Ultimate pull-out force was recorded for each pin and fixation strength was calculated (pull-out force / surface area of the pin).

\section{Histomorphometry}

Pins for histomorphometry were excised leaving a sufficient bone collar ( $5 \mathrm{~mm}$ minimum) around the pin, placed in $10 \%$ neutral buffered formalin, and shipped for histology slide preparation. Histology samples were embedded in an acrylic resin (Technovit 7200), sectioned and stained with Sanderson's Rapid Bone Stain. Digital photos of the slides were taken and image analysis was carried out using the colour recognition software in BioQuant. The bone-pin contact was measured and the scores were reported as a percentage of the pin surface area. Region of Interest encompassed the contact area along the full length of the interface between the bone defect surface and the pin surface.

\section{Statistical analysis}

Influence of the gentamicin-releasing coating on bacterial growth around the miniature stems was determined through comparison of the integrated photon flux around miniature stems with HA- or PLGA-gentamicin-HAcoatings using the unpaired Student's $t$-test, accepting $p \leq 0.05$ as statistically significant. Likewise, for the animal experiments the influence of the PLGA-gentamicinHA-coated pins on bone fixation, osseointegration, and infection resistance was determined through comparison of the fixation strength, percentage of bone-implant contact, and bacterial and neutrophil count in the animals groups with an HA-coated pin using the unpaired Student's $t$-test, accepting $p \leq 0.05$ as statistically significant.

\section{Results}

\section{Gentamicin release}

PLGA-gentamicin-HA-coatings demonstrate an initial burst release of around $95 \%$ of the gentamicin incorporated within the first $1-2 \mathrm{~h}$, followed by slow release of an additional $2 \%$ up to $6 \mathrm{~h}$. After about $168 \mathrm{~h}, 100 \%$ of the gentamicin was released from the PLGA-gentamicin-HAcoating (Fig. 2). SEM micrographs (Fig. 1) indicate that the PLGA-overlayer had disappeared within $336 \mathrm{~h}$, leaving the surface structure of the HA-coating intact.

\section{Antibacterial efficacy}

All staphylococcal strains, including gentamicin-resistant S. epidermidis 7388 and S. epidermidis 7391 are inhibited in their growth on agar during the first $24 \mathrm{~h}$ of gentamicin release from the coating (Fig. 3). The growth inhibition observed towards resistant strains can be attributed to the high initial burst release of the gentamicin from the coating. The antibacterial efficacy of the PLGA-gentamicin-HAcoating gradually decreases with time. Antibacterial efficacy disappears most readily for the gentamicinresistant strains while some residual antibacterial activity is seen for the most sensitive strains after $96 \mathrm{~h}$ (Fig. 3). No zones of inhibition were observed around HA-coated coupons without gentamicin.

\section{Bacterial killing in interfacial gap model}

At a bacterial challenge of 10 bacteria $/ \mathrm{cm}^{2}$ substratum surface, HA-coated coupons allowed growth of around 27 CFUs per coupon in the confined spacing between coupons and the Petrifilm, regardless of the staphylococcal strain involved, whereas no CFUs or in a few occasions 


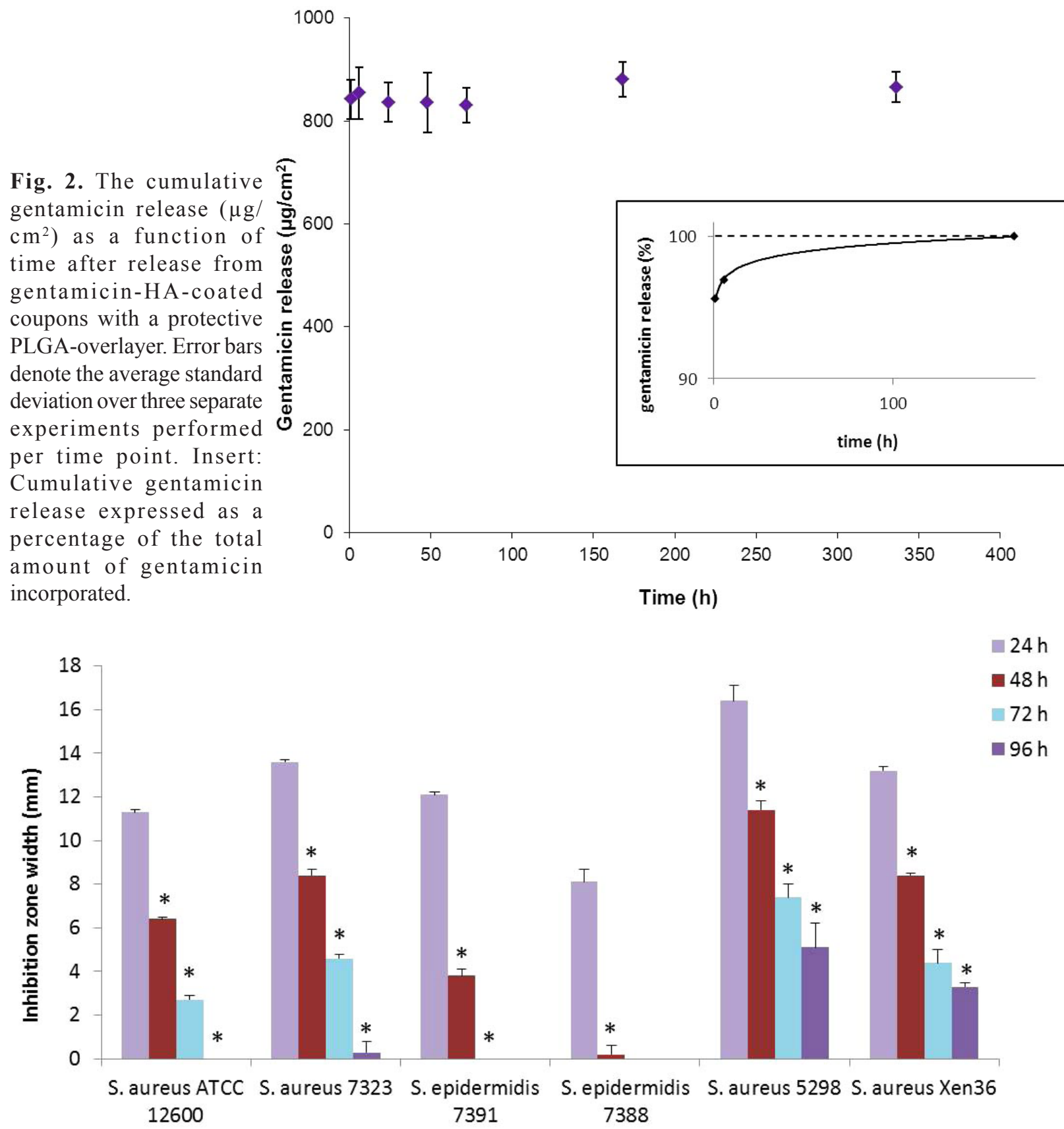

Fig. 3. Width of the zones of inhibition ( $\mathrm{mm}$ ) around gentamicin-HA-coated titanium coupons with a protective PLGAoverlayer on TSA plates as a function of time for six different staphylococcal strains. Growth inhibition zones were measured $24 \mathrm{~h}$ after inoculation, after which coupons were transferred to a freshly inoculated agar plate and incubated for another $24 \mathrm{~h}$. This procedure was repeated every $24 \mathrm{~h}$ to determine the longevity of the antibiotic release up to 4 days. Data represent averages over three separate experiments with error bars indicating the standard deviation. For each strain, significant differences $(p<0.05)$ within a time series with respect to the day before is indicated by $*$.

1 or 2 CFUs, were seen in the confined space between PLGA-gentamicin-HA-coated coupons and the Petrifilm until a bacterial challenge of $10^{7}$ bacteria $/ \mathrm{cm}^{2}$ was reached. Note that at a challenge of $10^{7}$ bacteria $/ \mathrm{cm}^{2}$, representing a clinically unlikely high total challenge, no CFUs were seen, not even for the gentamicin-resistant strains included.

\section{Longitudinal antibacterial efficacy in geometrically- relevant model}

Our data indicate that the gentamicin-susceptibility of bioluminescent $S$. aureus Xen36 is within the range of the other staphylococcal strains used (Fig. 3).
Photon fluxes arising from bioluminescent $S$. aureus Xen36 colonising the miniature stem and its surrounding become measurable after $30-40 \mathrm{~h}$ of growth around HA-coated stems (Fig. 4) and increase more than two log-units with time up to $60 \mathrm{~h}$ (statistically significant at $p=0.005$ ) after which the agar started to dry out, in a fashion resembling a normal bacterial growth curve. No measurable photon fluxes arise from colonising staphylococci when a PLGA-gentamicin-HA-coated stem is inserted in bacterially contaminated agar, indicating the antibacterial efficacy of the coating. 


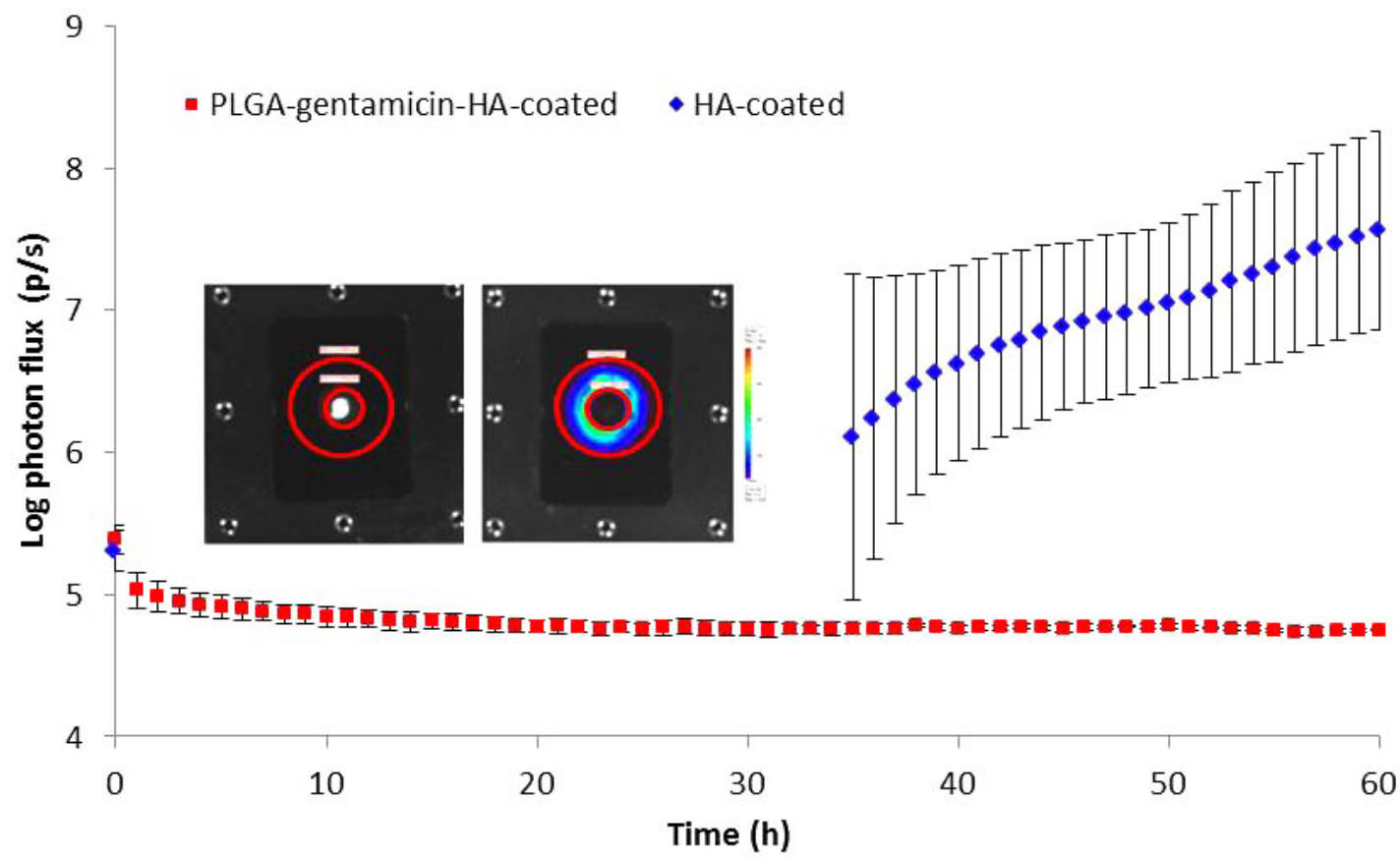

Fig. 4. Bioluminescence imaging of staphylococcal growth around miniature stems. Photon fluxes arising from a circular shell around miniature stems mounted in an agar mould contaminated with bioluminescent $S$. aureus Xen36 for HA-coated and PLGA-gentamicin-HA-coated stems as a function of time. All experiments were done in triplicate and data represent averages $\pm S D$ s. Insert: top-view of the bioluminescence signal around a miniature stem with (left) and without (right) a PLGA-gentamicin-releasing coating (indicated by the smallest red circle) in an agar mould, contaminated with bioluminescent $S$. aureus Xen36 after $31 \mathrm{~h}$ of incubation at $37{ }^{\circ} \mathrm{C}$. Bioluminescence is displayed on a pseudo-colour scale, high numbers of photons per second (p/s) appear red, while low numbers appear blue. The circular shell in between the red circles indicates the ROI for quantitative analysis of the bioluminescence.

\section{Animal experiments - infection prophylaxis model} HA- and PLGA-gentamicin-HA-coated pins were inserted in bacterially contaminated medullary canals in rabbits, defining "infection" as staphylococcal presence at the bone-implant interface, i.e. colonisation of the pin surface and in surrounding tissue. Accordingly, infection rates were $100 \%$ (7 out of 7 animals) for the rabbits with HAcoated pins and $0 \%$ ( 0 out of 7 animals) for the rabbits with PLGA-gentamicin-HA-coated pins. High levels of staphylococci were recovered from the femora of rabbits implanted with an HA-coated pin, while all rabbits implanted with a PLGA-gentamicin-HA-coated pin failed to produce bacterial colonies from either the femur or pin samples (Fig. 5a), yielding a statistically significant reduction $(p=0.001)$.

The infected animals did not show any signs of systemic septic disease during the entire observation period. Furthermore, body temperatures recorded during the study were comparable to pre-operative values for both groups. Noteworthy clinical findings (dehiscence or/and erythema) were limited to some animals implanted with an HA-coated pin. Mean body weight loss was slightly larger (not statistically significant) for animals implanted with the HA-coated pin (10\% weight loss) compared to animals with a PLGA-gentamicin-HA-coated pin $(5 \%$ weight loss). Haematological analyses in animals implanted with
HA-coated or PLGA-gentamicin-HA-coated pins showed a significant reduction in neutrophil ( $p=0.003$; Fig. 5b), basophil ( $p=0.035$; Fig. $5 \mathrm{c})$, and monocyte ( $p=0.027$; Fig. $5 d$ ) counts for the PLGA-gentamicin-HA group after implantation compared to the HA group. Accordingly total leukocyte counts were significantly $(p=0.023)$ higher in animals implanted with HA-coated $\left(9.85 \times 10^{3} /\right.$ $\mu \mathrm{L})$ than in animals with PLGA-gentamicin-HA-coated pins $\left(6.85 \times 10^{3} / \mu \mathrm{L}\right)$. In addition, platelet counts in animals implanted with PLGA-gentamicin-HA-coated pins showed a significant reduction ( $p=0.002$; Fig. 5e) after implantation compared to the HA group. No significant differences were observed between both groups in eosinophil, lymphocyte, erythrocyte, and absolute reticulocyte counts, and in haemoglobin and haematocrit values.

\section{Animal experiments - bone ingrowth model}

Noteworthy clinical findings were observed in two animals, but resolved prior to euthanisation. During week 2 and 3, one animal had impaired hind limb function on the right side, which was implanted with PLGA-gentamicin-HAcoated pins, while another animal (implanted with HAcoated pins) had swelling on the left hind limb at week 3. Incidentally, the average amount of PLGA on two pins decreased with $61 \%$ and $96 \%$ after 1 and 4 weeks, as 
A

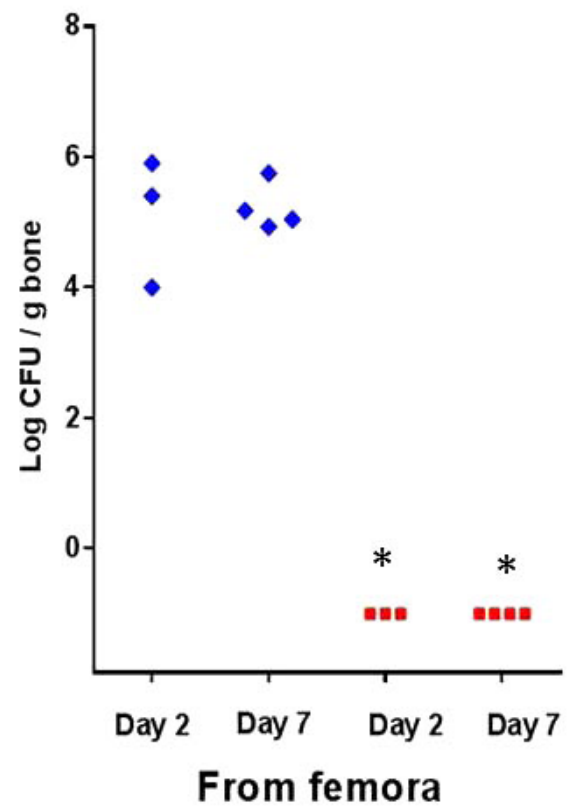

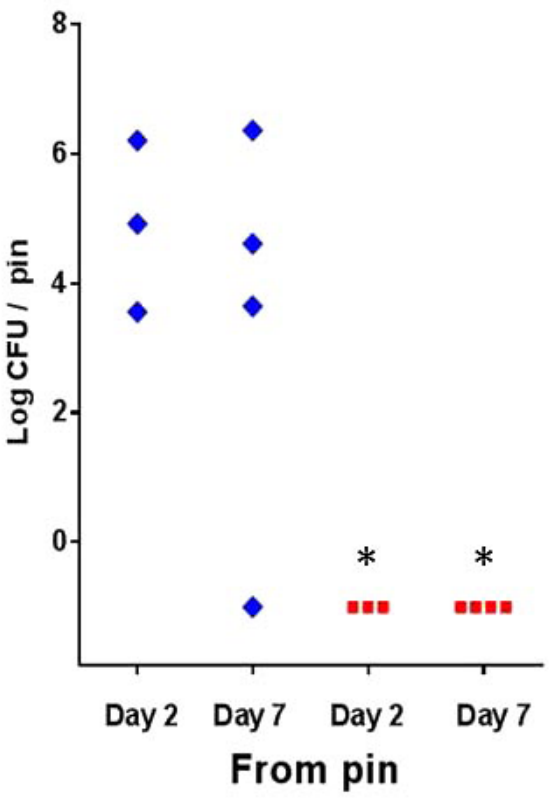

C

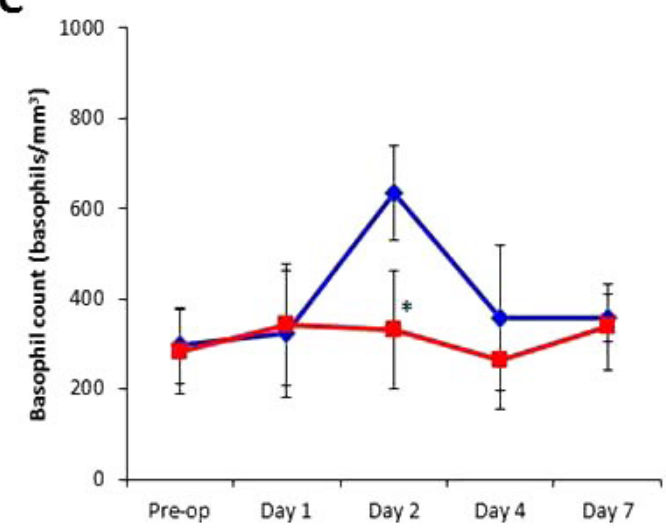

$\mathbf{E}$

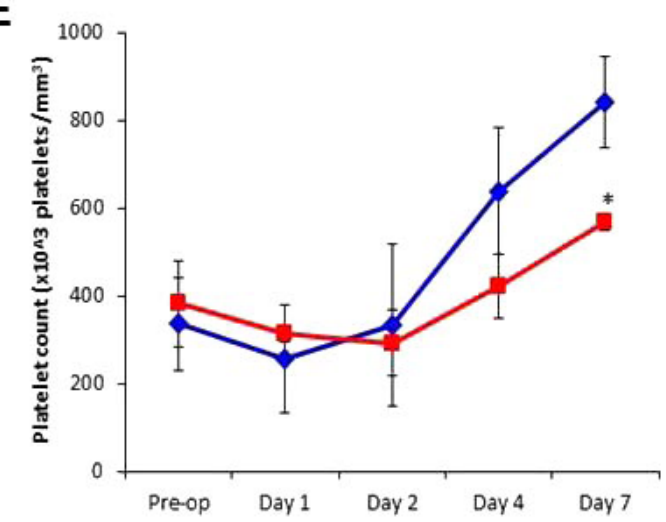

Fig. 5. Infection prevention with PLGA-gentamicin-HA-coated pins in a rabbit model. (A) Number of staphylococci recovered from femora and the pin itself at day 2 and 7 after insertion of HA-coated or PLGA-gentamicin-HA-coated pins in the medullary canal of rabbits. The medullary canal was contaminated with $1 \times 10^{5} \mathrm{CFU}$ of $S$. aureus ATCC 25923 prior to insertion of the pin. *denotes statistical significance at $p<0.05$ between PLGA-gentamicin-HA-coated and HA-coated. (B) Neutrophil counts (cells $/ \mathrm{mm}^{3}$ ) for HA-coated and PLGA-gentamicin-HA-coated pins in the medullary canal of rabbits. The medullary canal was contaminated with $1 \times 10^{5} \mathrm{CFU} /$ site of $S$. aureus ATCC 25923 prior to insertion of the pin. Haematological evaluations were done pre-operative and 1, 2, 4 and 7 days post-operatively. Data represent mean \pm standard deviations. *denotes statistical significance at $p<0.05$ between PLGA-gentamicinHA-coated and HA-coated. (C) As in Fig. 5b, for basophil counts. (D) As in Fig. 5b, for monocyte counts. (E) As in Fig 5 b, for platelet counts. 
Table 1. A comparison of the pre- and post-exposure antibacterial efficacy of gentamicin-HA-coatings in absence and presence of a protective PLGA-overlayer against gentamicin-resistant $S$. epidermidis 7388 , obtained prior to and after exposure of samples for $2 \mathrm{~h}$ in sterile PBS at $37^{\circ} \mathrm{C}$. Data represent averages over three separate experiments with \pm indicating the standard deviation.

\begin{tabular}{|l|c|}
\hline \multicolumn{2}{|c|}{ Pre-exposure efficacy } \\
\hline Coating & Number of CFU per coupon \\
\hline HA-coated & $28 \pm 3^{\mathrm{a}}$ \\
\hline $\begin{array}{l}\text { PLGA-gentamicin- } \\
\text { HA-coated }\end{array}$ & $0 \pm 0^{\mathrm{b}}$ \\
\hline \multicolumn{2}{|c|}{ Post-exposure efficacy } \\
\hline $\begin{array}{l}\text { Gentamicin-HA-coated } \\
\text { (no PLGA-overlayer) }\end{array}$ & $21 \pm 14^{\mathrm{c}}$ \\
\hline $\begin{array}{l}\text { PLGA-gentamicin- } \\
\text { HA-coated }\end{array}$ & $9 \pm 9^{\mathrm{a}, \mathrm{b}, \mathrm{c}}$ \\
\hline
\end{tabular}

a significantly different at $p=0.026$

${ }^{\mathrm{b}}$ no significant difference at $p=0.158$

${ }^{\mathrm{c}}$ no significant difference at $p=0.280$

determined by Cordis Corporation/Conor Medsystems, LLC, Fremont, US). No PLGA was detected on explanted pins after 12 weeks.

At 4 weeks, PLGA-gentamicin-HA-coated pins had lower fixation strength than HA-coated pins (Fig. 6a; $p=0.184)$. Nevertheless, the mechanical strength of the interface after 12 weeks was higher $(p=0.094)$ for the PLGA-gentamicin-HA-coated pins (Fig. 6a), ensuring better bone fixation in time.

Image analysis showed that mean overall percentages of bone-implant contact after 4 weeks were $40.0 \%$ for the HA-coated pins and $31.8 \%$ for the PLGA-gentamicinHA-coated pins (Fig. 6b; $p=0.0001$ ). After 12 weeks, HA-coated pins still showed slightly higher percentages of bone-implant contact (Fig. 6b), but this difference did not reach statistical significance $(p=0.365)$.

\section{Discussion}

The peri-prosthetic region in total joint arthroplasties is highly sensitive for bacterial biofilm formation (Campoccia et al., 2006). Fast tissue integration of HA-coatings is considered to reduce the risk of biofilm formation after peri-operative bacterial contamination of the implant and its surrounding (Geesink et al., 1987; Søballe et al., 1990; Dhert et al., 1993). However, Vogely et al. showed in a rabbit infection model that HA-coated implants had a higher infection susceptibility compared to uncoated titanium implants (Vogely et al., 2000) which negates the advantage of better bone integration and implant fixation (Oosterbos et al., 2002) and underscores the need for infection prophylaxis in cementless applications. Currently, there are no strategies available for local antibiotic delivery from cementless prostheses. HA is mostly applied to

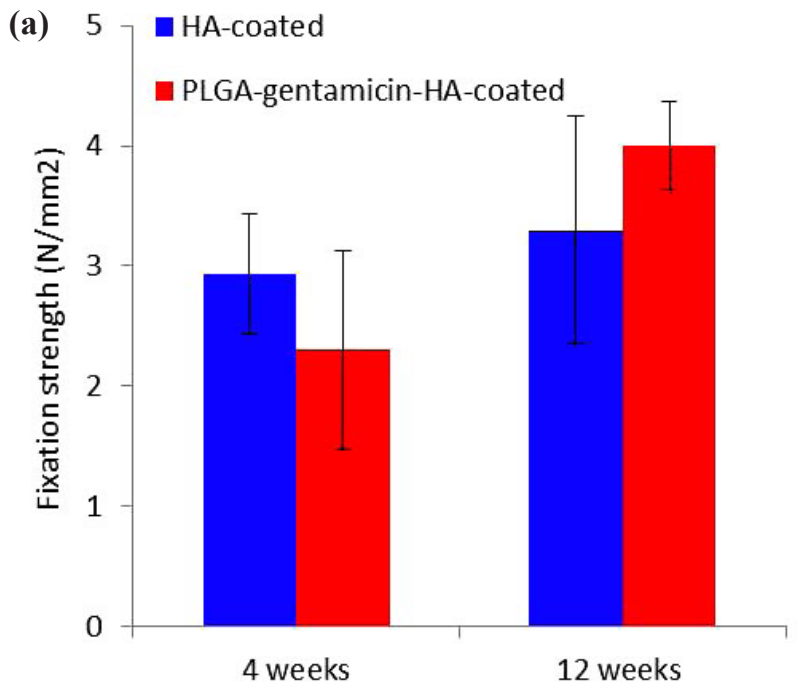

(b)

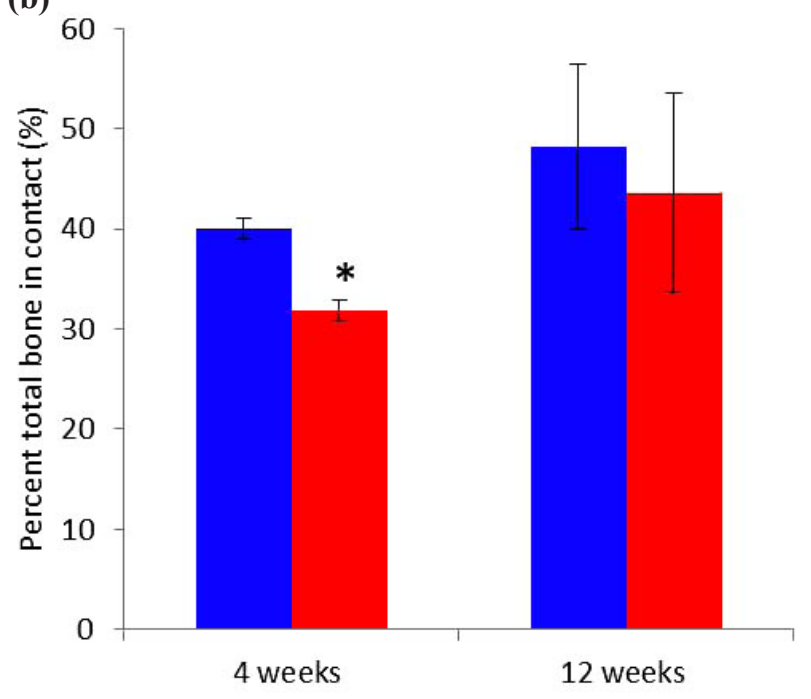

Fig. 6. Bone fixation and osseointegration with PLGAgentamicin-HA-coated pins in a canine condylar defect model. Data represent mean \pm standard deviations and *denotes statistical significance at $p<0.05$ between PLGA-gentamicin-HA-coated and HA-coated. (a) Fixation strength $\left(\mathrm{N} / \mathrm{mm}^{2}\right)$ for HA-coated and PLGAgentamicin-HA-coated pins in the distal femoral condyle of beagles. Pull-out testing was done 4 and 12 weeks post-operatively. (b) Osseointegration, expressed by amount of bone-implant contact at week 4 and 12 after insertion of HA-coated or PLGAgentamicin-HA-coated pins in the distal femoral condyle of beagles. Results are reported as a percentage of the implant surface area.

prosthetic surfaces by plasma spraying and the high processing temperatures associated with plasma spraying make incorporation of antibiotics impossible (Stigter et al., 2002). Incorporation of antibiotics in HA-coatings on titanium prostheses has been established using a "biomimetic" coating technology at $37^{\circ} \mathrm{C}$ with deposition of amorphous calcium phosphate on titanium followed by immersion of the prostheses in a supersaturated calcium phosphate solution containing the antibiotics (Stigter et al., 2004). However, the dose of antibiotics that could be 
incorporated this way is very limited and about 300 times lower than the gentamicin dose applied in our current PLGA-gentamicin-HA-coating, making this an unsuitable way for effective prophylaxis. Moreover, these coatings suffer from a rapid wash-out by body fluids (Radin et al., 1997): almost $100 \%$ of incorporated gentamicin was released within $1 \mathrm{~h}$ (Stigter et al., 2004). The coating investigated here protects the antibiotic sprayed onto the HA-coating through a PLGA-overlayer to yield an antibacterially effective release of gentamicin over clinically relevant time scales of up to 4 days, which is in fact longer than currently achieved using pre-operative antibiotics, usually given as a single dose $60 \mathrm{~min}$ before the surgical procedure (Bratzler et al., 2013). Although the feature of burst release within the first hours of exposure of the coating to a fluid may seem disappointing, this high burst release is important in order to kill bacteria introduced during the surgery (Knobben et al., 2006). At the same time, gentamicin release is fully confined to about 7 days which presents a clear advantage over the use of antibiotic-loaded bone cements in cemented applications, demonstrating a relatively low concentration tail-release of antibiotics, thereby limiting the risk of development of antibiotic-resistant strains (Thomes et al., 2002).

One of the critically important considerations when evaluating new antimicrobial technologies is the selection of appropriate and relevant in vitro models. The antibacterial efficacy of our PLGA-gentamicin-HA-coating was evaluated in three different in vitro systems and in an in vivo animal model. While zones of inhibition are wellaccepted and effective for comparing antibacterial efficacies of an antibiotic, they are not necessarily representative of the clinical situation. In orthopaedic prostheses, the clinical situation is characterised by both close proximity between the prosthesis and the bone surface, and limited fluid volumes and flow. Therefore, we studied staphylococcal survival in a confined space using a Petrifilm assay, as previously developed and published (Neut et al., 2011). Appropriate and clinically relevant in vitro systems and in vivo animal models are especially important in the evaluation of coatings in orthopaedics intended to reduce infection rates, because clinical studies in humans to demonstrate statistically significant reductions in infection rates are practically impossible due to the high number of patients required for such studies. In the hypothetical case, where the efficacy of a coating in reducing the incidence of infection has to be demonstrated in a clinical trial, a simple power calculation shows that studies aiming to demonstrate a $50 \%$ reduction - in an existing infection incidence of $2 \%$ at a conservative statistical significance of $p<0.05-$ requires the inclusion of around 5,000 patients, who must be followed longitudinally over several years (Darouiche et al., 1999). Such statistical considerations place a heavy burden on the selection of proper in vitro and in vivo animal experiments, although demonstration of the incidence of infection, as opposed to a reduction in biofilm formation, also requires large animal cohorts. All three in vitro systems applied here demonstrate antibacterial efficacy of our PLGA-gentamicin-HA-coatings, most notably so against gentamicin-resistant strains at very high bacterial challenge concentrations of up to $1 \times 10^{7}$ bacteria $/ \mathrm{cm}^{2}$. Importantly, these in vitro results are confirmed in an animal experiment. The animal study had a limited, but sufficient power to yield statistically significant conclusions and support the findings of our in vitro methods, as currently the use of large numbers of animals in vivo is becoming increasingly troublesome (Richmond, 2002).

Although there are several published studies that investigate the in vivo efficacy of antibiotic releasing coatings for the prevention of infection (Giavaresi et al., 2014), relatively fewer studies employ HA-coatings to do so. Alt et al. (2006) reported on the efficacy of two different gentamicin-HA-coatings on steel K-wires in the prevention of infection. They showed good results, as infection rates decreased from $88 \%$ for HA-coated $\mathrm{K}$-wires to $0 \%$ for both types of gentamicin-HA-coated K-wires. More recently, Moojen et al. (2009) investigated the efficacy of tobramycin-HA coated implants in preventing infection. For a $S$. aureus challenge in a rabbit model $6 \%$ of the tobramycin-HA-coated titanium foam rods were infected after 28 days, compared to $53 \%$ and $67 \%$ for the HA-coated titanium and uncoated titanium rods, respectively. Both studies, however, have no protective PLGA-overlayer, unlike our current PLGA-gentamicinHA-coating. This thin biodegradable overlayer serves to protect the gentamicin layer during transit and surgical implantation, even when the prosthesis is hammered into a tight bone junction and the coating becomes disrupted, gentamicin release will occur at the implant-bone junction. The protective effects of the PLGA-overlayer are demonstrated in Table 1, showing antibacterial efficacy of the coatings after $2 \mathrm{~h}$ of exposure to a fluid (PBS in the present example). The PLGA-overlayer clearly slows down the release of gentamicin due to a longer diffusion trajectory, which is of clinical importance when the prosthesis might become in contact with body fluids prior to final insertion in the bone. The gentamicin-coated tibial nail that has been recently approved for clinical application in Europe and Canada, is equipped with a poly-DL-lactide (PDLLA)-layer in which gentamicin is dispersed (Schmidmaier et al., 2006), but its degradation is considerably slower than of our coating through the use of higher-molecular weight PDLLA (30 kDa versus $17 \mathrm{kDa}$ in our coating). This makes the gentamicin tibial nail with PDLLA-layer well suited for its application in trauma, where high antibiotic levels are needed during longer periods than in our application, which is aimed to prevent the development of infection due to peri-operative bacterial contamination of an implant and its surrounding tissue.

The prophylactic gentamicin-HA-coating with a protective PLGA-overlayer developed here has the ability to resist local infection; all animals in the PLGAgentamicin-HA-coated group were free of infection despite an inoculation dose of $10^{5} \mathrm{CFU} /$ site of $S$. aureus. Infiltration of granulocytes is one of the first steps of an inflammatory process and generally encompasses neutrophils but also, to a much smaller, extent basophils (Schutte et al., 2009). Yet, significant reductions in both neutrophil and basophil counts in animals implanted with PLGA-gentamicin-HA-coated pins were noticed. As neutrophils are the primary white blood cells that respond 
to invading $S$. aureus in order to bind and ingest them (Rigby and DeLeo, 2012), this is an important finding. It is widely recognised that bacteria causing prosthetic hip infections grow in biofilms. Therefore, any antibiotic coating for cementless hip prostheses should be capable of preventing bacterial biofilm formation. Our animal model showed complete bacterial growth inhibition on all PLGA-gentamicin-HA pins implanted, both 2 and 7 days after placement. It seems presumable that "sealing" the gentamicin-HA-coating with a PLGA-overlayer bears the risk of impairing bone ingrowth, which determines the long-term survival of cementless prostheses in total joint replacements. However, 12 weeks after implantation, PLGA-gentamicin-HA-coated pins performed slightly better in a pull-out test than did HA-coated pins and this effect on bone fixation strength of a gentamicin coating has been noticed before (Fassbender et al., 2013). Neither mechanically nor histomorphometrically were there any statistically significant differences, suggesting that our biodegradable PLGA-gentamicin-HA-coating does not impair long-term bone ingrowth.

\section{Conclusions}

The gentamicin-HA-coating with a protective PLGAoverlayer shows good antibacterial efficacy in vitro, killing even gentamicin-resistant staphylococcal strains in the confined space of a simulated interfacial gap, as initially existing between a cementless prosthesis and cancellous bone. Moreover, we were able to longitudinally demonstrate the absence of bacterial growth of contaminating staphylococci along the PLGAgentamicin-HA-coated stems for at least $60 \mathrm{~h}$. These in vitro results were all in line with results obtained in a rabbit model, demonstrating infection prophylaxis for at least 7 days, while not impairing bone fixation and osseointegration 12 weeks after implantation in a nonrodent model. Our biodegradable PLGA-gentamicinHA-coating is a so-called combination device: clinically approved components (HA, a drug and a biodegradable polymer overlayer) are combined into a single platform. Combination devices are offered a unique regulatory review process to facilitate translation to clinical application (Wu and Grainger, 2006), although they still undergo lengthy approval processes that include in vitro testing, animal studies and clinical trials. Importantly, and in line with what is needed for the approval of a new drug (Web ref. 4), animal studies have been carried out in rodent-like and nonrodent species. Inclusion of a non-rodent species is required in the safety assessment of pharmaceuticals to limit the uncertainty in the extrapolation process from animal toxicity data to the human situation (Web ref. 5). Based on these corroborative results, our PLGA-gentamicin-HAcoating has a high potential, as an extremely appreciated clinical option for infection prophylaxis in cementless total joint replacement. Regulatory agencies, especially in the USA have been critical toward antibiotic-releasing coatings, fearing that long-term tail release of the antibiotic, as from gentamicin-loaded bone cements, stimulates the development of resistance among bacterial strains.
Importantly, we demonstrate that the current coating effectively overcomes this critique, as antibiotic release is completed after dissolution of the PLGA-overcoat. Moreover, inclusion of other antibiotics in the coating will not affect the release mechanism.

\section{Acknowledgements}

This study was funded in part by the University Medical Center Groningen, The Netherlands, DePuy Synthes, United Kingdom and SASA BV, The Netherlands. Authors were employed by their own organisations. HJB is also director-owner of SASA BV. The authors declare no potential conflicts of interest with respect to authorship and/or publication of this article. Opinions and assertions contained herein are those of the authors and are not construed as necessarily representing views of the funding organisations or their respective employers.

\section{References}

Alt V, Bitschnau A, Osterling J, Sewing A, Meyer C, Kraus R, SA Meissner SA, Wenisch S, Domann E, Schnettler R (2006) The effects of combined gentamicinhydroxyapatite coating for cementless joint prostheses on the reduction of infection rates in a rabbit infection prophylaxis model. Biomaterials 27: 4627-4634.

Alt V, Bitschnau A, Böhner F, Heerich KE, Magesin E, Sewing A, Pavlidis T, Szalay G, Heiss C, Thormann U, Hartmann S, Pabst W, Wenisch S, Schnettler R (2011) Effects of gentamicin and gentamicin-RGD coatings on bone ingrowth and biocompatibility of cementless joint prostheses: an experimental study in rabbits. Acta Biomater 7: 1274-1280.

Bobyn JD, Stackpool GJ, Hacking SA, Tanzer M, Krygier JJ (1999) Characteristics of bone ingrowth and interface mechanics of a new porous tantalum biomaterial. J Bone Joint Surg Br 81: 907-914.

Bratzler DW, Dellinger EP, Olsen KM, Perl TM, Auwaerter PG, Bolon MK, Fish DN, Napolitano LM, Sawyer RG, Slain D, Steinberg JP, Weinstein RA; American Society of Health-System Pharmacists (ASHP); Infectious Diseases Society of America (IDSA); Surgical Infection Society (SIS); Society for Healthcare Epidemiology of America (SHEA) (2013) Clinical practice guidelines for antimicrobial prophylaxis in surgery. Surg Infect (Larchmt) 14: 73-156.

Campoccia D, Montanaro L, Arciola CR (2006) the significance of infection related to orthopedic devices and issues of antibiotic resistance. Biomaterials 27: 2331-2339.

Dale H, Hallan G, Espehaug B, Havelin LI, Engesaeter LB (2009) Increasing risk of revision due to deep infection after hip arthroplasty. Acta Orthop 80: 639-645.

Darouiche RO, Raad II, Heard SO, Thornby JI, Wenker OC, Gabrielli A, Berg J, Khardori N, Hanna H, Hachem R, Harris RL, Mayhall G (1999) A comparison of two antimicrobial - impregnated central venous catheters. Catheter Study Group. N Eng J Med 340: 1-8. 
Deacon JM, Pagliaro AJ, Zelicof SB, Horowitz HW (1996) Prophylactic use of antibiotics for procedures after total joint replacement. J Bone Joint Surg Am 78: 17551770 .

Dhert WJA, Klein CPAT, Jansen JA, Van der Velde AE, De Vries RC, Rozing PM, De Groot K (1993) A histological and histomorphometrical investigation of fluorapatite, magnesiumwhitlockite, and hydroxylapatite plasma-sprayed coatings in goats. J Biomed Mater Res 27: 127-138.

Engesaeter LB, Lie SA, Espehaug B, Furnes O, Vollset SE, Havelin LI (2003) Antibiotic prophylaxis in total hip arthroplasty: effects of antibiotic prophylaxis systemically and in bone cement on the revision rate of 22,170 primary hip replacements followed 0-14 years in the Norwegian Arthroplasty Register. Acta Orthop Scand 74: 644-6451.

Fassbender M, Minkwitz S, Kronbach Z, Strobel C, Kadow-Romacker A, Schmidmaier G, Wildemann B (2013) Local gentamicin application does not interfere with bone healing in a rat model. Bone 55: 298-304.

Fitzgerald RH (1979) Microbiologic environment of the conventional operating room. Arch Surg 114: 772-775.

Geesink RGT, de Groot K, Klein CPAT (1987) Chemical implant fixation using hydroxyl-apatite coatings. The development of a human total hip prosthesis for chemical fixation to bone using hydroxyl-apatite coatings on titanium substrates. Clin Orthop Relat Res 225: $147-$ 170 .

Giavaresi G, Meani E, Sartori M, Ferrari A, Bellini D, Sacchetta AC, Meraner J, Sambri A, Vocale C, Sambri V, Fini M, Romanò CL (2014) Efficacy of antibacterial-loaded coating in an in vivo model of acutely highly contaminated implant. Int Orthop 38: 1505-1512.

Gristina AG (1987) Biomaterial-centered infection: microbial adhesion versus tissue integration. Science 237: 1588-1595.

Hamilton H, Jamieson J (2008) Deep infection in total hip arthroplasty. Can J Surg 51: 111-117.

Helwig P, Morlock J, Oberst M, Hauschild O, Hübner J, Borde J, Südkamp NP, Konstantinidis L (2014) Periprosthetic joint infection - effect on quality of life. Int Orthop 38: 1077-1081.

Hess DJ, Henry-Stanley MJ, Wells CL (2011) Gentamicin promotes Staphylococcus aureus biofilms on silk suture. J Surg Res 170: 302-308.

Knobben BAS, Van Horn JR, Van der Mei HC, Busscher HJ (2006) Evaluation of measures to decrease intra-operative bacterial contamination in orthopaedic implant surgery. J Hosp Infect 62:174-180.

Kurtz SM, Ong KL, Lau E, Bozic KJ (2014) Impact of the economic downturn on total joint replacement demand in the United States: updated projections to 2021. J Bone Joint Surg Am 96: 624-630.

Malchau H, Herberts P, Eisler T, Garellick G, Söderman P (2002) The Swedish total hip replacement register. J Bone Joint Surg Am 84: 2-20.

Markmiller M, Weisss T, Kreuz P, Rüter A, Konrad G (2011) Partial weightbearing is not necessary after cementless total hip arthroplasty: a two-year prospective randomized study on 100 patients. Int Orthop 35:11391143.
Moojen DJF, Vogely HCh, Fleer A, Nikkels PGJ, Higham PA, Verbout AJ, Castelein RM, Dhert WJA (2009) Prophylaxis of infection and effects on osseointegration using a tobramycin-periapatite coating on titanium implants - an experimental study in the rabbit. J Orthop Res 27: 710-716.

Nemes S, Gordon M, Rogmark C, Rolfson O (2014) Projections of total hip replacement in Sweden from 2013 to 2030. Acta Orthop 85: 238-243.

Neut D, Dijkstra RJB, Thompson JI, Van der Mei HC, Busscher HJ (2011) Antibacterial efficacy of a new gentamicin-coating for cementless prostheses compared to gentamicin-loaded bone cement. J Orthop Res 29: 16541661.

Neut D, Dijkstra RJB, Thompson JI, Van der Mei HC, Busscher HJ (2012) A gentamicin-releasing coating for cementless hip prostheses-Longitudinal evaluation of efficacy using in vitro bio-optical imaging and its widespectrum antibacterial efficacy. J Biomed Mater Res A 100: 3220-3226.

Oosterbos CJM, Vogely HCh, Nijhof MW, Fleer A, Verbout AJ, Tonino AJ, Dhert WJA (2002) Osseointegration of hydroxyapatite-coated and noncoated Ti6Al4V implants in the presence of local infection: a comparative histomorphometrical study in rabbits. J Biomed Mater Res 60: 339-347.

Oosterbos CJM, Rahmy AIA, Tonino AJ, Witpeerd W (2004) High survival rate of hydroxyapatite-coated hip prostheses: 100 consecutive hips followed for 10 years. Acta Orthop Scand 75: 127-133.

Parvizi J, Suh DH, Jafari SM, Mullan A, Purtill JJ (2011) Aseptic loosening of total hip arthroplasty: infection always should be ruled out. Clin Orthop Relat Res 469: 1401-1405.

Radin S, Campbell JT, Ducheyne P, Cuckler JM (1997) Calcium phosphate ceramic coatings as carriers of vancomycin. Biomaterials 18: 777-782.

Reignier C, Barbour V (2011) Manufacturing Process: All White Powder Is Not HA. In: Vidalain J-P, Selmi TAS, Beverland D, Young S, Board T, Brumby S, editors. The CORAIL ${ }^{\circledR}$ Hip System: A Practical Approach Based on 25 Years of Experience. Springer, pages 31-34.

Richmond J (2002) Refinement, reduction, and replacement of animal use for regulatory testing: future improvements and implementation within the regulatory framework. ILAR J 43: S63-68.

Rigby KM, DeLeo FR (2012) Neutrophils in innate host defense against Staphylococcus aureus infections. Semin Immunopathol 34: 237-259.

Schmidmaier G, Lucke M, Wildemann B, Haas NP, Raschke M (2006) Prophylaxis and treatment of implantrelated infections by antibiotic-coated implants: a review. Injury 37: S105-112.

Schutte RJ, Xie L, Klitzman B, Reichert WM (2009) In vivo cytokine-associated responses to biomaterials. Biomaterials 30: 160-168.

Søballe K, Hansen ES, Brockstedt-Rasmussen H, Pedersen CM, Bünger C (1990) Hydroxyapatite coating enhances fixation of porous coated implants. A comparison in dogs between press fit and noninterference fit. Acta Orthop Scand 61: 299-306. 
Søballe K, Hansen ES, Brockstedt-Rasmussen H, Bünger C (1993) Hydroxyapatite coating converts fibrous tissue to bone around loaded implants. J Bone Joint Surg Br 75: 270-278.

Sossai D, Dagnino G, Sanguineti F, Franchin F (2011) Mobile laminar air flow screen for additional operating room ventilation: reduction of intraoperative bacterial contamination during total knee arthroplasty. J Orthop Traumatol 12: 207-211.

Stigter M, de Groot K, Layrolle P (2002) Incorporation of tobramycin into biomimetic hydroxyapatite coating on titanium. Biomaterials 23: 4143-4153.

Stigter M, Bezemer J, de Groot K, Layroll P (2004). Incorporation of different antibiotics into carbonated hydroxyapatite coatings on titanium implants, release and antibiotic efficacy. J Control Release 99: 127-137.

Subbiahdoss G, Kuijer R, Busscher HJ, Van der Mei HC (2010) Mammalian cell growth versus biofilm formation on biomaterial surfaces in an in vitro post-operative contamination model. Microbiology 156: 3073-3078.

Thomes B, Murray P, Bouchier-Hayes D (2002) Development of resistant strains of Staphylococcus epidermidis on gentamicin-loaded bone cement in vivo. $\mathrm{J}$ Bone Joint Surg Br 84: 758-760.

Tunney MM, Dunne N, Einarsson G, McDowell A, Kerr A, Patrick S (2007) Biofilm formation by bacteria isolated from retrieved failed prosthetic hip implants in an in vitro model of hip arthroplasty antibiotic prophylaxis. J Orthop Res 25: 2-10.

Turner AS. Animal models of osteoporosis - necessity and limitations (2001) Eur Cell Mater 1: 66-81.

Vanhegan IS, Malik AK, Jayakumar P, Ul Islam S, Haddad FS (2012) A financial analysis of revision hip arthroplasty: The economic burden in relation to the national tariff. J Bone Joint Surg Br 94: 619-623.

Verkkala K, Eklund A, Ojajärvi J, Tiittanen L, Hoborn J, Mäkelä P (1998) The conventionally ventilated operating theatre and air contamination control during cardiac surgery - bacteriological and particulate matter control garment options for low level contamination. Eur J Cardiothorac Surg 14: 206-210.

Vogely HCh, Oosterbos CJM, Puts EWA, Nijhof MW, Nikkels PGJ, Fleer A, Tonino AJ, Dhert WJA, Verbout AJ (2000) Effects of hydroxyapatite coating on Ti-6A1-4V implant-site infection in a rabbit tibial model. J Orthop Res 18: 485-493.

Waldman BJ, Mont MA, Hungerford DS (1997) Total knee arthroplasty infections associated with dental procedures. Clin Orthop Relat Res 343: 164-172.

Wang J, Zhu C, Cheng T, Peng X, Zhang W, Qin H, Zhang X (2013) A systematic review and meta-analysis of antibiotic-impregnated bone cement use in primary total hip or knee arthroplasty. PLoS One 8: e82745.

Wu P, Grainger DW (2006) Drug/device combinations for local drug therapies and infection prophylaxis. Biomaterials 27: 2450-2467.

Zimmerli W, Trampuz A, Ochsner PE (2004) Prostheticjoint infections. N Engl J Med 351: 1645-1654.

\section{Web references}

1. OECD, "Health at a glance 2011" Report, OECD Publishing 2011, p. 92-93. Available from URL: http:// www.oecd.org/els/health-systems/49105858.pdf [14-052014].

2. Dunbar MJ. Cemented femoral fixation: the North Atlantic divide. Orthopedics 2009;32. Available from URL: http://www.healio.com/orthopedics/hip/journals/ OR T H O / \% 7 B F 053 E D 41 - 0247 - 4 B 1 F - B 693 366B47958039\%7D/Cemented-Femoral-Fixation-TheNorth-Atlantic-Divide?full=1 [14-05-2014].

3. DePuy International Ltd. An implantable medical device. International patent PCT/EP2009/063588. Online 2010. Available from URL:

http://patentscope.wipo.int/search/en/WO2010043710 [14-05-2014].

4. Science, Medicine, and Animals. Committee to Update Science, Medicine, and Animals; Institute for Laboratory Animal Research; Division on Earth and Life Studies; National Research Council. National Academies Press, Washington DC, US, 2004. Safety Testing, available from URL: http://www.ncbi.nlm.nih.gov/books/NBK24645/ [14-05-2014].

5. European Commission, Scientific Committee on Health and Environmental Risks, 2009. Non-human primates in research and safety testing. Available from URL: http:// ec.europa.eu/health/opinions/en/non-human-primates/13/2-research-safety-testing.htm [14-05-2014].

\section{Discussion with Reviewers}

Reviewer III: If the polymer coating allows most fractional drug release within a few hours, why use PLGA at all? Why not use a slowly soluble calcium phosphate coating?

Authors: The thin PLGA-overlayer serves as a biodegradable layer to protect the gentamicin layer during transit and surgical implantation and not a priori to control antibiotic release. A calcium-phosphate coating was not used because calcium-phosphate is not strong enough during surgical implantation.

Reviewer III: What antibiotic dosing requirements are considered for this possible clinical application?

Authors: The gentamicin surface concentration was chosen, because its antibacterial efficacy matches with the antibacterial efficacy of gentamicin-loaded bone cement (Neut et al., 2011, text reference).

Reviewer III: Is local cell toxicity from rapid drug dose dumping an issue for these closed compartment models? Authors: Our Beagle dog study shows (Figure 6) that the local gentamicin application does not negatively interfere with the long-term healing process, but even shows a small stimulation of the fixation strength. Furthermore, in vitro studies with osteosarcoma cells did not show any cytotoxic effects of the coating (Web ref. 3, text reference). 
Reviewer III: The future of gentamicin releasing technologies may be influenced by increasing gentamicin resistance amongst staphylococci. This is known to be a problem in gentamicin releasing bone cements, as the authors are well aware. How do the authors see this issue in terms of the performance of the described gentamicin releasing technology?

Authors: We are indeed aware of the increasing gentamicin resistance in staphylococci causing prosthetic joint infections. We chose gentamicin because of its widespread clinical use, but our coating may as well be used in combination with other antibiotics.

Reviewer V: Insertion of an artificial joint is a vigorous act using a hammer forcing the implant in a press-fit fixation in a pre-reamed bone bed. Is the coating strong enough to withstand these forces? What would be the effect if the coating is disrupted in parts? Will the implant than be contaminated only on these specific points or will the burst release of gentamicin kind of cover these areas?
Authors: We have not performed any stability testing of the coating. However, since this is a release coating and not a (mono-) molecular coating, hammer blows may disrupt the integrity of the coating, but this will yield an increased burst-release utmost, since the antibiotic is in all cases made locally available.

Reviewer V: Around $2 / 3$ of blood loss in THR occur after surgery has finished with blood flowing from the medullary canal along the implant to the joint. How much wash out of antibiotics will be possible without dropping the antibiotic concentration below the MIC?

Authors: When the released antibiotic falls below the MIC levels in vivo cannot be answered in any in vitro study. The answer critically depends on the volume used to release the antibiotics in and the turn-over of the fluid in that volume. Gentamicin is highly hydrophilic and spontaneous release will occur when left unprotected on a surface. The protective effect of the PLGA- overlayer in a moist environment clearly follows from the data in Table 1. 